\title{
Cholecystokinin Receptor Antagonism of Stimulated Pancreatic and Gastric Secretion
}

\author{
Michael W. Mulholland, M.D., ${ }^{*}$ and Haile T. Debas, M.D. $\dagger$ \\ *Department of Surgery, University of Michigan, Ann Arbor, Michigan 49109, and $\nmid$ Department of Surgery, \\ University of California, San Francisco, California 94143
}

Submitted for publication August 22, 1988

The effects of cholecystokinin receptor antagonist, dipentyl-3,4-dichloraproglumide (DDP), on stimulated pancreatic and gastric secretion were studied in the rat. DDP dose-dependently inhibited cholecystokinin-stimulated amylase release from dispersed acinar cells. In vivo, DDP inhibited cholecystokinin octapeptide-stimulated amylase and protein secretion. DDP also inhibited pentagastrin-stimulated gastric acid secretion in vivo. Meal-stimulated acid output was decreased by 34\% (DDP $400 \mu \mathrm{g} / \mathrm{kg} / \mathrm{hr}$ ) but responsiveness to histamine or parachlorophenyl- $\boldsymbol{\gamma}$-aminobutyric acid was unchanged.

(1) 1989 Academic Press, Inc.

\section{INTRODUCTION}

A number of compounds have been developed recently with activities as receptor antagonists for peptide hormones of the gastrointestinal tract. These compounds have exciting potential as probes for elucidation of control mechanisms of gastrointestinal function and for investigation of the role of gastrointestinal hormones in various disease states. Future therapeutic uses of specific receptor antagonists is an important prospect.

A number of compounds have been described which demonstrate cholecystokinin (CCK) receptor antagonism in vitro. Four general classes of CCK receptor antagonists have been recognized: (1) derivatives of cyclic nucleotides such as dibutyryl cyclic GMP; (2) fragments or analogs of the C-terminal region of CCK; (3) nonpeptide compounds such as asperlicin, derived from Apergillus alliaceus; and (4) amino acid derivatives such as benzotript or proglumide [1-8]. While the various agents have been useful for investigation of pancreatic function in vitro, most of these compounds have pharmacologic deficits which limit their use for in vivo experimentation or for therapy. For example, both benzotript and dibutyryl cyclic GMP are toxic at doses which achieve significant inhibitory actions in vivo [9]. CCK analogs and C-terminal peptide fragments require intravenous infusion and are rapidly degraded in serum or blood [10]. Benzotript and proglumide are limited by unacceptably low potencies.
Among the amino acid derivatives, a series of glutaramic acid congeners have recently been reported which are potent antagonists of the pancreatic stimulatory actions of CCK in vitro [11]. Several of the agents demonstrate greatly improved in vitro potency when compared to benzotript or proglumide. Glutaramic acid derivatives have been reported to inhibit binding of CCK to guinea pig gallbladder and to rat pancreatic tissues and brain [12, 13]. Glutaramic acid derivatives have been reported by Niederau et al. to competitively inhibit the binding of CCK to dispersed rat acinar cells and to dose-dependently inhibit amylase release from dispersed cells [13]. The current study was designed to correlate in vitro and in vivo activities of one of the most potent of these compounds, dipentyl-3,4-dichloroproglumide, on CCK-stimulated pancreatic secretion. In addition, because of the close structural similarities between the active sites of the CCK and gastrin molecules, the specificity of this receptor antagonist for in vivo experimentation was assessed by examining its effects on stimulated gastric acid secretion.

\section{MATERIALS AND METHODS}

\section{Substances}

DL - 4 - (3,4 - Dimethylbenzoylamino) - 5 - (di - $n$ - pentylamino)-5-oxopentanoic acid (dipentyl-3,4-dichloroproglumide-referred to subsequently in this text as DDP) was a generous gift of Dr. I. Setnikar, Rotta Laboratorium, Milan, Italy. For in vivo experiments, DDP was administered after it was dissolved in $0.9 \% \mathrm{NaCl}$. Cholecystokinin octapeptide (CCK8; Peninsula Labs, Belmont, CA), and pentagastrin (Ayerst Laboratories) were prepared as solutions in $0.1 \%$ bovine serum albumin (Sigma Chemical Co., St. Louis, MO). Histamine (Eli Lilly, Indianapolis, IN), and para-chlorophenyl- $\gamma$-aminobutyric acid (PCPGABA, Geigy Pharmaceuticals, Summit, NJ) were dissolved in $0.9 \% \mathrm{NaCl}$. Liquid peptone meals (Bactopeptone; Difco Laboratories, Detroit, MI) were prepared at $5 \%(\mathrm{w} / \mathrm{v})$ concentrations; the osmolarity and $\mathrm{pH}$ of each meal were adjusted to $320 \mathrm{mOsm}$ and 5.5 by addition of $\mathrm{NaCl}$ and $4 \mathrm{~N} \mathrm{HCl}$, respectively. All other chemicals and supplies were purchased from Sigma. 


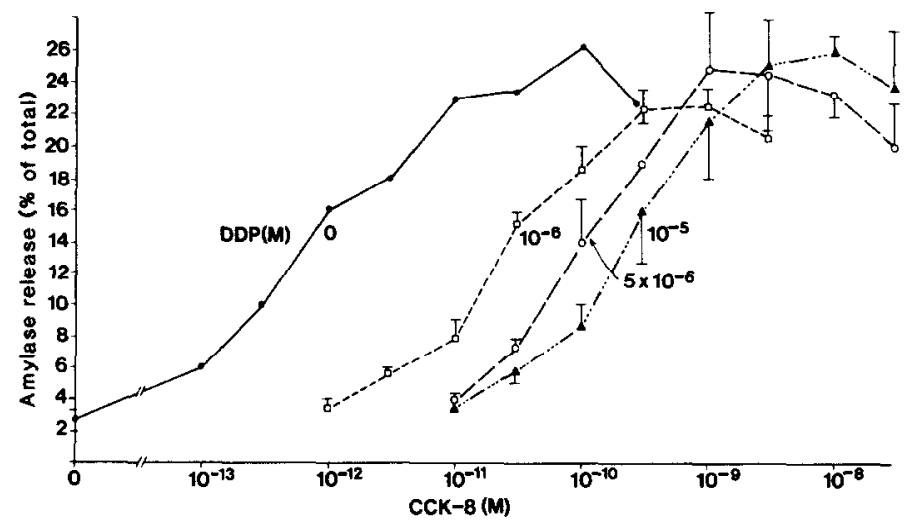

FIG. 1. Effect of DDP on CCK-stimulated amylase release from dispersed rat acinar cells. Acinar cells were stimulated with increasing doses of CCK8 in the presence of $10^{-6}, 5 \times 10^{-6}$, and $10^{-5} M$ DDP. Results are calculated as percentages of total amylase after subtraction of basal release. Each value was determined in duplicate. The curves represent mean values from six separate experiments. Standard errors were less than $10 \%$ in all instances.

\section{Isolated Pancreatic Acini}

The method for preparation of isolated rat pancreatic acini is a modification of the methods of Amsterdam et al. [14] and Williams et al. [15]. Male Sprague-Dawley rats, weighing $200-250 \mathrm{~g}$, were fasted for $16 \mathrm{hr}$ before sacrifice. The pancreas was removed and carefully dissected free of nonpancreatic tissue. With a 25 -gauge needle, the pancreas was injected with $5 \mathrm{ml}$ of highly purified collagenase solution [Krebs-Ringer-Hepes buffer plus 0.1 $\mathrm{mg} / \mathrm{ml}$ soybean trypsin inhibitor (Sigma), $0.1 \mathrm{mM} \mathrm{Ca}{ }^{2+}$, $11.1 \mathrm{mM}$ glucose, and $0.1 \mathrm{mg} / \mathrm{ml}$ highly purified collagenase (Worthington Biochemicals)]. Pancreatic tissue was incubated for three periods of 15 to $30 \mathrm{~min}$ with collagenase solution at $37^{\circ} \mathrm{C}$. The tissue was dissociated by forceful aspiration through three Pasteur pipets of decreasing size. Debris was removed by passage through $\mathrm{Ni}$ tex gauge $(200 \mu \mathrm{m})$. Isolated acini were centrifuged in $4 \%$ albumin and then resuspended in buffer. For dose-response studies, the acini were incubated with various concentrations of secretogogue and antagonists for $20 \mathrm{~min}$ at $37^{\circ} \mathrm{C}$ in a shaking water bath. Amylase release into the supernatant was assayed spectrophotometrically by a modification of the method described by Bernfeld [16]. Amylase release was expressed as the percentage of total amylase present.

A Schild plot for inhibition of amylase release by DDP was calculated from CCK dose-response curves in the presence of increasing amounts of the inhibitor [17]. For each shift in the dose-response curves, the ratios of the $50 \%$ inhibitory dose of CCK $\left(\mathrm{ID}_{50}\right)$ in the presence of DDP to CCK alone were calculated. The negative log of the molar doses of DDP were plotted against the respective $\mathrm{ID}_{50}$ values. The least-squares method was used to find the regression line.

\section{In Vivo Pancreatic Secretory Studies}

In vivo effects of DDP on pancreatic exocrine secretion were examined in urethane-anesthetized animals. The National Research Council's Guide for Care and Use of Laboratory Animals was followed. After a 16-hr fast, rats were injected intraperitoneally with urethane $(1.25 \mathrm{~g} / \mathrm{kg})$. The pancreas was exposed through a short midline incision. A small incision was made in the pancreatic duct just proximal to the duodenal wall; the duct was cannulated with polyethylene tubing. Bile-pancreatic juice was collected by gravity drainage in 30 -min samples. Through a separate duodenal puncture site, a small polyethylene catheter was inserted for infusion of bile pancreatic juice at the rate of $1.5 \mathrm{cc} / \mathrm{hr}$. The infused bile-pancreatic juice had been previously collected from normal rats. A 23gauge needle was placed in the femoral vein for infusion of test substances; for those experiments in which more than one peptide or test substance was infused, bilateral femoral catheters were used.

Pancreatic secretory volume was recorded and samples of pancreatic secretion were assayed for protein and amylase. Protein content was determined by the method of Lowry et al. [18].

\section{In Vivo Gastric Secretory Studies}

The effects of DDP on in vivo gastric acid secretion were studied using an acute gastric fistula preparation. After a 16-hr fast, rats were anesthetized with intraperitoneal urethane. The trachea was cannulated and the esophagus was ligated in the neck. Vagal nerve trunks were carefully preserved during esophageal ligation. Through a small midline incision, the stomach was exposed and a double-lumen gastric cannula was inserted via the forestomach. The pylorus was ligated. Venous access was achieved with femoral vein catheters. For studies that included intravenous or subcutaneous administration of test substances, the gastric lumen was rinsed with 20

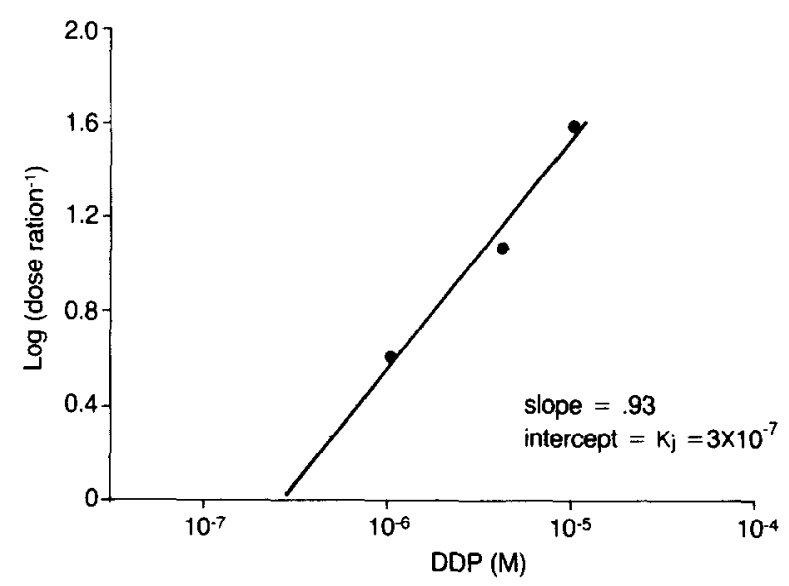

FIG. 2. Schild plot for inhibition of CCK-stimulated amylase release with increasing concentrations of DDP. Slope equals 0.93 . The intercept with the horizontal axis, $K_{\mathrm{i}}$, is $3 \times 10^{-7} \mathrm{M}$. 

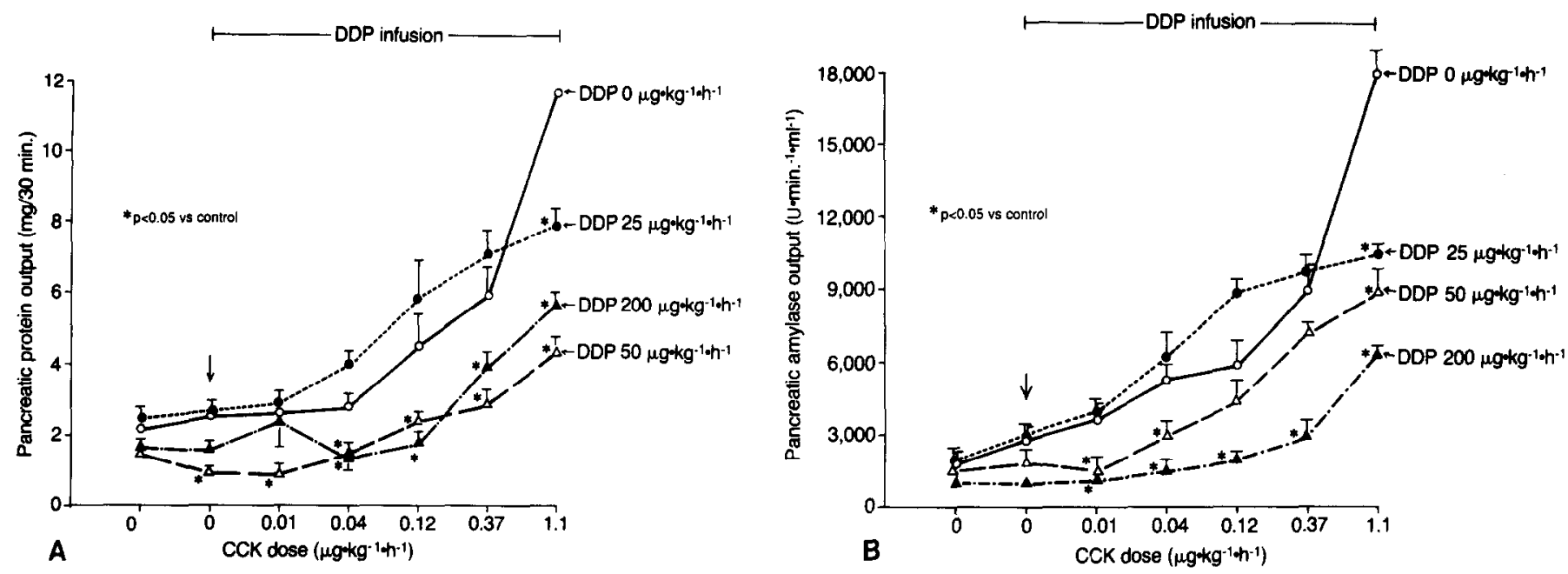

FIG. 3. Effects of DDP on CCK-stimulated pancreatic output of protein (A) and amylase (B). Pancreatic secretion was collected in 30-min samples. DDP was infused intravenously at doses of $0,25,50$, and $200 \mu \mathrm{g} / \mathrm{kg} / \mathrm{hr}$ starting $30 \mathrm{~min}$ before stepwise, increasing doses of CCK8. The curves represent mean values from groups of six animals each.

cc of saline every $10 \mathrm{~min}$. Acid production was measured by titration of the gastric rinse solution with $0.1 \mathrm{~N} \mathrm{NaOH}$ to neutrality. For liquid meal studies, the meal was instilled at a volume of $10 \mathrm{ml}$. After $10 \mathrm{~min}$, the test meal was evacuated, and the stomach was rinsed with $20 \mathrm{cc}$ of saline. Acid production was measured for the liquid meal stimulus by titration to $\mathrm{pH}$ 5.5. Acid secretion was expressed as milliequivalents per $10 \mathrm{~min}$.

\section{Statistical Analysis}

Data from in vivo experiments were calculated as group means \pm SEM and were analyzed using a one-way analysis of variance. Significance was assumed for $P$ values less than 0.05 .

\section{RESULTS}

\section{Effects on in Vitro Amylase Release}

Increasing concentrations of CCK8 dose-dependently stimulated amylase release from dispersed rat acinar cells. Amylase release was maximal at $10^{-10} M$, with decreased responses at higher concentrations (Fig. 1). The CCK dose-response curve was shifted to the right in the presence of the CCK antagonist, DDP. The magnitude of the shift was related to the concentration of the antagonist. However, maximal amylase release, expressed as percentage of total amylase, was unaffected by increasing concentrations of DDP.

Analysis of the data by a Schild plot demonstrates that DDP acts as a competitive antagonist of CCK stimulation of amylase secretion (Fig. 2). The $K_{\mathrm{i}}$, determined from the intercept with the horizontal axis, was $3 \times 10^{-7} M$. The slope of the line was 0.93 .

\section{Effects on in Vivo Pancreatic Secretion}

Increasing concentrations of CCK8, administered intravenously, dose-dependently increased pancreatic amylase output. Maximum amylase secretion was observed at a CCK dose of $1.1 \mu \mathrm{g} / \mathrm{kg} / \mathrm{hr}$, the highest dose employed. DDP administered intravenously for $30 \mathrm{~min}$ prior to CCK infusion did not alter basal protein or amylase output (Fig. 3). However, the antagonist (at doses of 50 and 200 $\mu \mathrm{g} / \mathrm{kg} / \mathrm{hr}$ ) caused significant inhibition of pancreatic amylase and total protein responses to CCK stimulation. The maximal pancreatic exocrine response to CCK stimulation was significantly decreased for all doses of DDP utilized (Fig. 3).

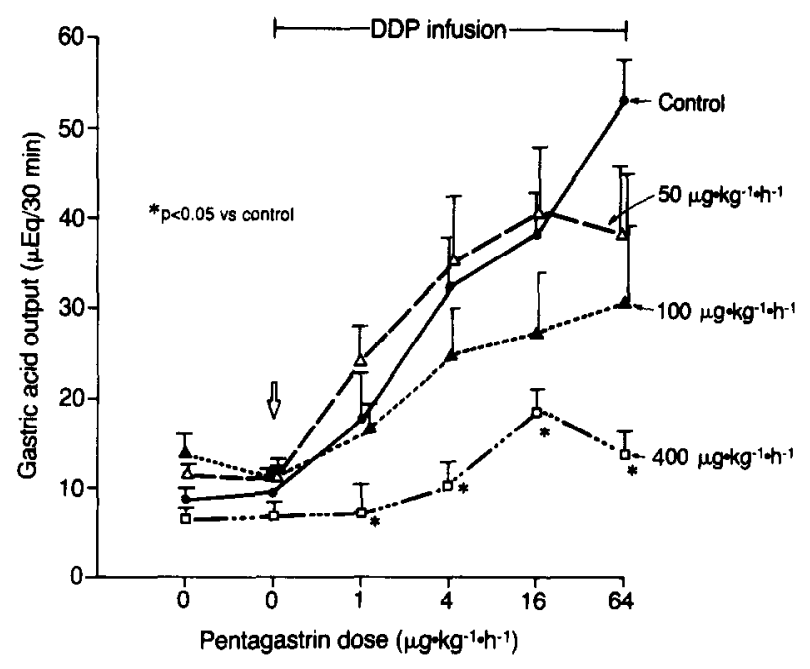

FIG. 4. Effect of DDP on pentagastrin-stimulated gastric acid output. Gastric secretion is expressed as group means for 30 -min collections. Each experimental group contained six animals. DDP was infused intravenously at doses of $0,50,100$, and $400 \mu \mathrm{g} / \mathrm{kg} / \mathrm{hr}$, beginning $30 \mathrm{~min}$ before increasing doses of pentagastrin. 

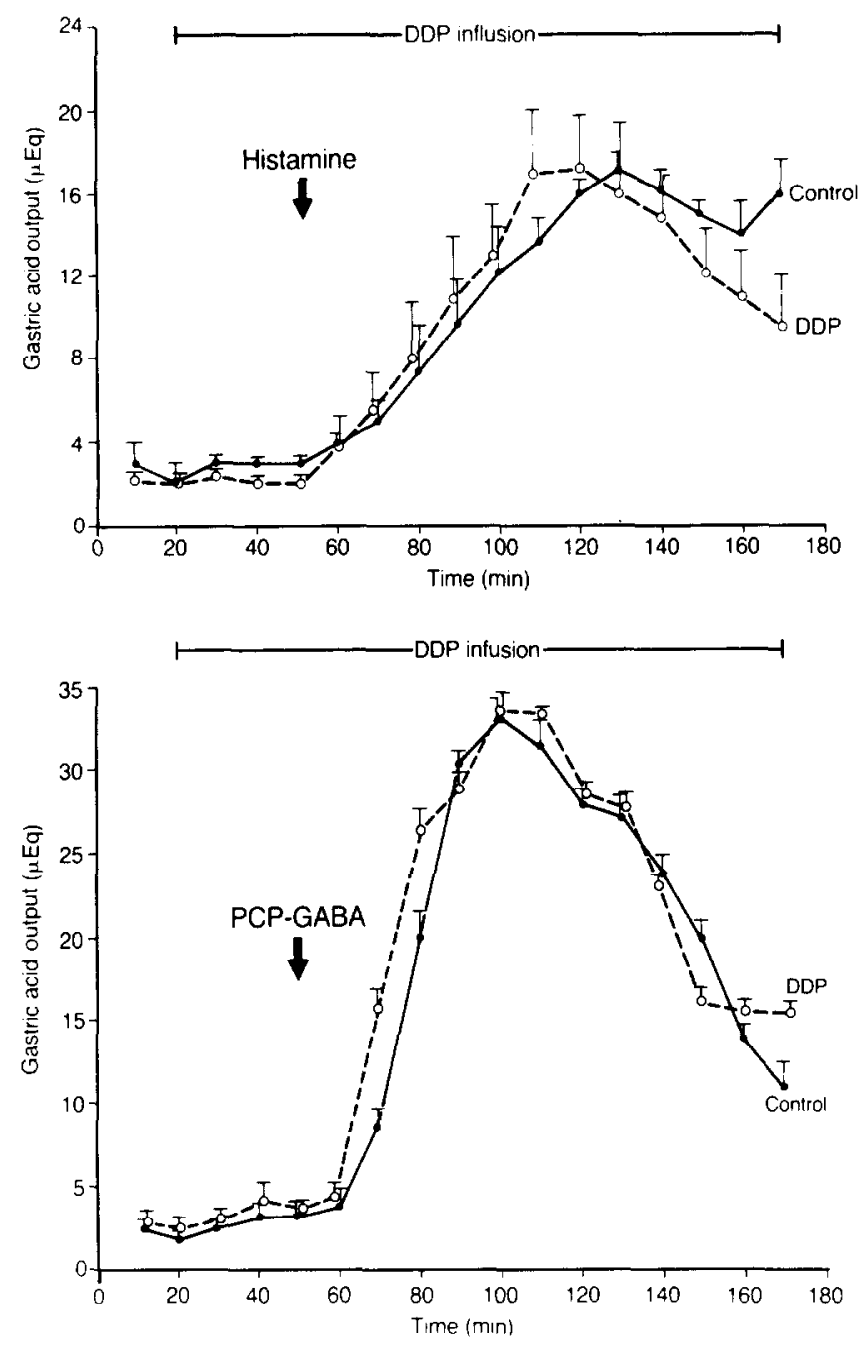

FIG. 5. Effect of DDP on gastric acid output in response to histamine or PCP-GABA. DDP at a dose of $400 \mu \mathrm{g} / \mathrm{kg} / \mathrm{hr}$ was infused intravenously starting $30 \mathrm{~min}$ prior to administration of histamine (10 $\mathrm{mg} / \mathrm{kg}$ subcutaneously) or PCP-GABA ( $4 \mathrm{mg} / \mathrm{kg}$ subcutaneously).

\section{Effects on in Vivo Gastric Acid Secretion}

Increasing concentrations of pentagastrin, ranging from 1 to $64 \mu \mathrm{g} / \mathrm{kg} / \mathrm{hr}$ caused dose-dependent increases in gastric acid output (Fig. 4). Decreases in pentagastrin-stimulated acid secretion were noted in association with DDP administration (Fig. 5). These differences achieved statistical significance at a dose of $400 \mu \mathrm{g} / \mathrm{kg} / \mathrm{hr}$. At this dose, DDP nearly abolished the gastric acid response to all doses of pentagastrin tested.

The in vivo specificity of DDP was demonstrated by the absence of significant effect on acid secretion stimulated by histamine or by the vagal stimulatory agent PCP-GABA (Fig. 5). However, DDP reduced 30-min peak acid output in response to a $5 \%$ liver meal by approximately $34 \%$ (Fig. 6).

\section{DISCUSSION}

Cholecystokinin is an important regulatory peptide with a wide distribution in the gut as well as the central and peripheral nervous systems [19]. The biological actions of CCK include regulation of pancreatic secretion and gallbladder contraction and modulation of gastrointestinal motility. Physiologic roles for CCK have been proposed for activities as diverse as neurotransmission and control of satiety. The availability of potent and specific CCK receptor antagonists for in vitro studies has helped define the role of $\mathrm{CCK}$ in a number of physiologic and pathologic states. However, while effective in vitro, most CCK receptor antagonists developed initially were not useful for in vivo investigations nor as potential therapeutic agents. Derivatives of cyclic nucleotides such as dibutyryl cGMP are potent inhibitors of CCK-stimulated amylase release in vitro but have significant toxicity in living animals [2]. Partial amino acid sequences of the biologically active $\mathrm{C}$ terminus of $\mathrm{CCK}$, for example, CCK(27-32) $-\mathrm{NH}_{2}$ and acetyl CCK(26-32)- $\mathrm{NH}_{2}$, also exhibit potent inhibition of CCK actions in vitro [3]. However, rapid enzymatic degradation of such peptide segments in serum precludes successful use in most living animal models [10].

Among amino acid congener CCK receptor antagonists, proglumide and benzotript are the best characterized and have been used to treat human subjects with peptic ulcer disease [20]. Both drugs have excellent clinical safety records, but low potency has limited their usefulness. DDP, which like proglumide and benzotript is a derivative of glutaramic acid, has a greatly increased inhibitory potency in vitro for CCK stimulation of pancreatic tissues. Niederau and co-workers have recently reported that the antagonist is $2500-4000$ times more potent than proglumide in the inhibition of CCK8-stimulated amylase release from dispersed rat acinar cells [13]. DDP demonstrated a similar increase in potency for inhibition of binding of ${ }^{125} \mathrm{I}-\mathrm{CCK}$ to rat pancreatic acini. The compound displayed competitive kinetics in studies of rat tissues in vitro [21].

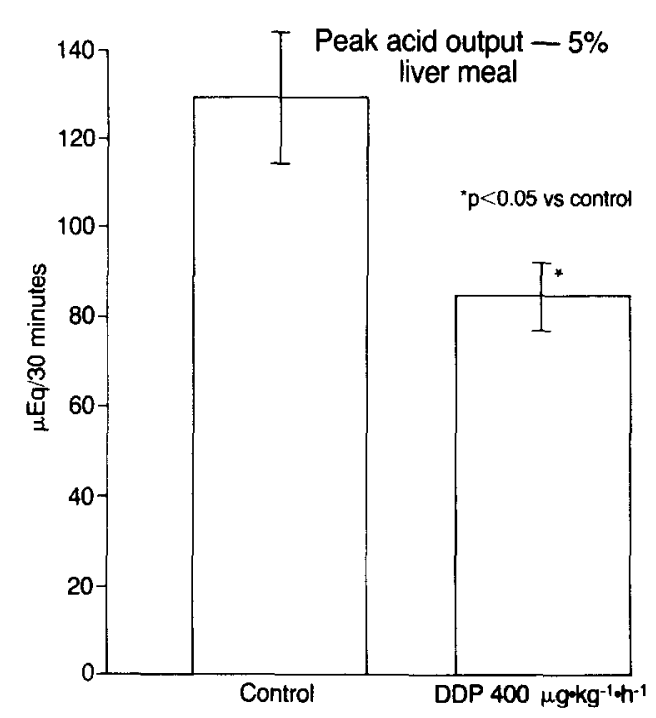

FIG. 6. Effects of DDP $(400 \mu \mathrm{g} / \mathrm{kg} / \mathrm{hr})$ on gastric acid secretion in response to $5 \%$ peptone meal. 
The current study confirms the ability of DDP to competitively inhibit CCK-stimulated amylase release from dispersed rat acinar cells. Increasing concentrations of the antagonist caused progressive shift of CCK dose-response curves to the right without altering maximal responses. Analysis of the data by the method of Schild yielded a $K_{\mathrm{i}}$ value of $3 \times 10^{-7} \mathrm{M}$. In addition, the study demonstrated that DDP effectively inhibited CCK-stimulated pancreatic exocrine secretion in vivo. Amylase secretion in vivo was dose-dependently inhibited by DDP; the degree of inhibition was significant for all doses of CCK when DDP was administered intravenously at a dose of $200 \mu \mathrm{g} / \mathrm{kg} / \mathrm{hr}$.

Because of the structural homology of the biologically active C-terminal regions of $\mathrm{CCK}$ and gastrin, it is not surprising that DDP also demonstrated inhibitory activity against pentagastrin-stimulated gastric acid secretion. Nearly total inhibition of acid secretion was observed at a dose of $400 \mu \mathrm{g} / \mathrm{kg} / \mathrm{hr}$. This finding suggests that in vivo experiments that employ high-dose DDP blockade to demonstrate CCK-specific actions must be interpreted with caution. DDP did not affect acid responses to histamine or PCP-GABA [22]. In contrast, DDP inhibited gastric acid responses to a liver extract meal by approximately $34 \%$. The inhibition-of-meal response was similar to that reported in rats by Goto and co-workers using a monoclonal antibody to gastrin [23].

In conclusion, dipentyl-3,4-dichloroproglumide is a potent inhibitor of CCK-stimulated pancreatic exocrine function, effective both in vitro and in vivo. However, the agent also demonstrated significant in vivo inhibition of pentagastrin-stimulated gastric acid secretion when higher doses were used. The antagonist may serve as a useful probe for the investigation of pancreatic and gastric pathophysiology. In the future, the agent may have potential as a therapeutic agent for selected pancreatic disease, an exciting and important prospect.

\section{REFERENCES}

1. Barlas, N., Jensen, R. T., Beinfeld, M. C., and Gardner, J. D. Cyclic nucleotide antagonists of cholecystokinin: Structure requirements for interaction with the cholecystokinin receptor. Amer. J. Physiol. 242: G161, 1982.

2. Peiken, S. R., Costenbader, C. L., and Gardner, J. D. Actions of derivatives of cyclic nucleotides on dispersed acini from guinea pig. Discovery of a competitive antagonist of the action of cholecystokinin. J. Biol. Chem. 254: 5321, 1979.

3. Gardner, J. D., Knight, M., Sutliff, V. E., Tamminga, C. A., and Jensen, R. T. Derivatives of CCK-(26-32) as cholecystokinin receptor antagonists in guinea pig pancreatic acini. Amer. J. Physiol. 246: G292, 1984.

4. Chang, R. S. L., Monaghan, R. L., Bimbaum, J., Stapley, E. D., Goetz, M. A., Albers-Schonberg, G., Patchett, A. A., Liesch, J. M., Hensens, O. D., and Springes, J. P. A nonpeptide cholecystokinin antagonist selective for peripheral tissues isolated from Aspergillus alliaceus. Science 230: 177, 1985.
5. Gardner, J. D., and Jensen, R. T. Cholecystokinin receptor antagonists. Amer. J. Physiol. 246: G471, 1984.

6. Hahne, W. F., Jensen, R. T., Lemp, G. F., and Gardner, J. D. Proglumide and benzotript: Members of a different class of cholecystokinin receptor antagonists. Proc. Natl. Acad. Sci. USA 78: 6304, 1981.

7. Niederau, C., Grendell, J. H., and Rothman, S. S. Effects of proglumide on ductal and basolateral secretion of digestive enzymes. Amer. J. Physiol. 249: G100, 1985.

8. Williams, G. A., Korc, M., and Dormer, R. L. Action of secretagogues on a new preparation of functionally intact, isolated pancreatic acinar. Amer. J. Physiol. 235: E517, 1978.

9. Grendell, J. H., and Niederau, C. Blockade of cholecystokinin receptors in the central nervous system may be fatal. Gastroenterology 88: 1405 (Ahstract), 1985.

10. Koulishcer, D., Morodet, L., and Deschodt-Lanckman, M. Degradation of cholecystokinin octapeptide, related fragments and analogs by human and rat plasma in vitro. Regul. Peptides 4: 127, 1982.

11. Makovec, F., Chiste, R., Bani, M., Revel, L., Setnikar, I., and Rovati, A. L. New glutaramic and aspartic derivatives with potent CCKantagonistic activity. Eur. J. Med. Chem. 21: 9, 1986.

12. Makovec, F., Bani, M., Cereda, R., Chiste, R., Pacini, M. A., Revel, L., and Rovati, L. C. Antispasmodic activity on the gallbladder of the mouse of CR 1409 (longlumide) a potent antagonist of peripheral CCK. Pharmacol. Res. Commun. 19: 41, 1987.

13. Niederau, C., Niederau, M., Williams, J. A., and Grendell, J. H. New proglumide-analogue cholecystokinin receptor antagonists: Very potent and selective for peripheral tissues. Amer. J. Physiol. 250: G856, 1986.

14. Amsterdam, A., Solomon, T. E., and Jamieson, J. D. Sequential dissociation of pancreas lobules, acini, and individual cells. In Methods in Cell Biology. New York: Academic Press, 1978. Vol. 20, pp. 361-378.

15. Williams, J. A., Korc, M., and Dormer, R. L. Actions of secretagogues on a new preparation of functionally intact, isolated pancreatic acini. Amer. J. Physiol. 235: E517, 1978.

16. Bernfeld, P. Amylases a and b. In S. P. Colowick and N. O. Kaplan (Eds.), Methods in Enzymology. New York: Academic Press, 1955. Pp. 149-158.

17. Schild, H. O. Drug-receptor interactions. In H. O. Schild (Ed.), Applied Pharmacology. Edinburgh/New York: Churchill-Livingstone, 1980. Pp. 5-18.

18. Lowry, O. H., Rosebrough, N. J., Farr, A. L., and Randall, R. J. Protein measurement with the Folin phenol reagent. J. Biol. Chem. 193: 265, 1951.

19. Dockray, G. J. Immunochemical evidence of cholecystokinin-like peptides in man. Nature (London) 264: 568, 1976.

20. Jager, H., Tzonev, E. V., Gronde, C. H. R., et al. Comparative clinical study of the preventive and therapeutic efficacy of proglumide and of cimetidine on stress ulcers in apoplectic patients. In Proceedings, Sixth International Symposium on Proglumide, Lisbon, September 1985, p. 111.

21. Makovec, F., Bani, M., Chiste, L., Revel, L., Rovati, L. C., and Setnikar, I. Different peripheral and central antagonist activity of new glutaramic acid derivatives on satiety inducted by cholecystokinin in rats. Regul. Peptides 16: 281, 1986.

22. Goto, Y., Tache, Y., Debas, H., and Novin, D. Gastric acid and vagus nerve response to GABA agonist baclofen. Life Sci. 36: 2471, 1985.

23. Goto, Y., Garcia, R., Katt, B. W., Debas, H. T., and Walsh, J. H. Importance of endogenous gastrin in gastric acid response to a meal in rat. Gastroenterology 90: 1434, 1986. 